\title{
Time to Reach Steady State and Prediction of Steady-State Concentrations for Drugs Obeying Michaelis-Menten Elimination Kinetics
}

\author{
John G. Wagner ${ }^{1,2}$ \\ Received October 19, 1977--Final January 6, 1978
}

\begin{abstract}
Using a numerical integration method, concentration-time data were simulated using the one-compartment open model both with bolus intravenous administration and oral administration (first-order absorption) after multiple doses administered at constant time intervals and for each model for five different doses. Constants used produced data very similar to those which have been reported for phenytoin in the literature. In the simulation of oral data, sufficient concentrations were recorded to allow estimation of the maximum $\left(\mathrm{C}_{\mathrm{n}}^{\max }\right)$, average $\left(\overline{\mathrm{C}}_{\mathrm{n}}\right)$, and minimum $\left(\mathrm{C}_{\mathrm{n}}^{\text {min }}\right)$ concentrations during each dosage interval, but for the intravenous data only $\mathrm{C}_{\mathrm{n}}^{\max }$ and $\mathrm{C}_{\mathrm{n}}^{\min }$ values were recorded. The approach to steady state was monoexponential for low doses and biexponential for higher doses. The half-life of the final first-order approach to the steady-state concentration was approximately linearly related to the final steady-state concentration. For the intravenous data the number of doses required to reach $95 \%$ of $\mathrm{C}_{s s}^{\min }$ was a linear function of $0.95 \mathrm{C}_{s s}^{\text {min }}$. A simple difference plot allows any given steady-state concentration of the three to be estimated from non-steady-state concentrations. When $C_{n}^{\text {min }}$ values are measured, as in therapeutic drug monitoring, the fitting of $\mathrm{C}_{s s}^{\text {min }}$ vs. dose rate $(\mathrm{D} / \tau)$ data leads to operationally useful parameters, $\mathrm{V}_{\mathrm{m}}^{a p p}$ and $\mathrm{K}_{\mathrm{m}}^{a p p}$, which are not the true kinetic parameters, $\mathrm{V}_{\mathrm{m}}$ and $\mathrm{K}_{\mathrm{m}}$, whereas fitting of $\overline{\mathrm{C}}_{s s}$ es $\mathrm{D} / \tau$ data does lead to estimation of $\mathrm{V}_{\mathrm{m}}$ and $\mathrm{K}_{\mathrm{m}}$.
\end{abstract}

KEY WORDS: time to reach steady state; prediction of steady-state concentrations; Michaelis-Menten elimination kinetics.

\section{INTRODUCTION}

The Michaelis-Menten equation (1) was first applied in pharmacokinetics to explain elimination of ethanol from human serum by Lundquist and Wolthers (2). Other applications of the equation were summarized by

\footnotetext{
${ }^{1}$ College of Pharmacy and Upjohn Center for Clinical Pharmacology, The University of Michigan, Ann Arbor, Michigan 48109.

${ }^{2}$ Address correspondence to Dr. John G. Wagner, Upjohn Center for Clinical Pharmacology, The University of Michigan Medical Center, Ann Arbor, MI 48109.
} 
Wagner (3). More recently the equation has been applied to serum and plasma concentrations of phenytoin (4-7). Some properties of the equation and its integrated form were given by Wagner (8). Tsuchiya and Levy (9) published some plots of the ratio plateau level/dose vs. dose after simulating multiple dose levels for the one-compartment open model with (a) first-order elimination, (b) Michaelis-Menten elimination, and (c) parallel first-order and Michaelis-Menten elimination. However, there appears to be no published information on the time required to reach steady-state levels when elimination obeys Michaelis-Menten kinetics. In the case of phenytoin monitoring, authors (5-7) are measuring $a$ phenytoin concentration at some time within one or more dosage intervals, but differ as to when during the dosage interval the sample is taken or after how many doses. Eadie (10) states that the " 5 times half-life rule works adequately" for phenytoin as for drugs eliminated by first-order kinetics. Intuitively, this appeared to be incorrect to this author. This study was undertaken to obtain quantitative information by a simulation technique concerning the time required to reach steady state and methods to predict steady-state concentrations from concentrations "observed" before steady-state was attained.

\section{THEORETICAL}

Equation 1 applies to the steady state for the one-compartment open model with constant-rate intravenous infusion and Michaelis-Menten elimination kinetics:

$$
k_{0}=V_{d} V_{m} C_{\mathrm{ss}} /\left(K_{m}+C_{\mathrm{ss}}\right)
$$

where $k_{0}$ is the constant infusion rate (mass/time), $V_{d}$ is the volume of distribution, $V_{m}$ is the maximal velocity [mass/(volume $\times$ tirne)] so that $V_{d} V_{m}$ is the maximal velocity (mass/time), $K_{m}$ is the Michaclis constant (mass/volume), and $C_{\mathrm{ss}}$ is the steady-state concentration (mass/volume). For the $n$-compartment open mammillary model with central compartment elimination only, equation 1 also applies, but $V_{d}$ is replaced by $V_{d \mathrm{ss}}$ as defined by

$$
V_{d \mathrm{ss}}=\left(1+k_{12} / k_{21}+\cdots+k_{1 n} / k_{n 1}\right) V_{p}
$$

where $k_{12}$ and $k_{21}$ are the transfer rate constants between compartments 1 and $2, k_{1 n}$ and $k_{n 1}$ are the transfer rate constants between compartment 1 and the $n$th compartment, and $V_{p}$ is the volume of the central compartment.

For intermittent intravenous administration with a dose $D$ administered every $\tau \mathrm{hr}$, equation 3 would apply, where the average steady-state 
concentration, $\vec{C}_{\mathrm{ss}}$, is given by equation 4 :

$$
\begin{gathered}
D / \tau=V_{d} V_{m} \bar{C}_{\mathrm{ss}} /\left(K_{m}+\bar{C}_{\mathrm{ss}}\right) \\
\bar{C}_{\mathrm{ss}}=\int_{0}^{\tau} C_{\mathrm{ss}}(t) d t / \tau
\end{gathered}
$$

Thus the $k_{0}$ of equation 1 is replaced by the "dose rate," $D / \tau$, in equation 3 and $C_{\mathrm{ss}}$ is replaced by $\bar{C}_{\mathrm{ss}}$.

Analogously, for oral administration one would expect equations 3 and 4 also to apply, since, as in linear pharmacokinetics, the absorption rate constant would not appear in such an equation; the only change would be that for oral administration the $D$ of equation 3 would mean the amount of drug which reaches the circulation intact.

In therapeutic drug monitoring the minimum concentrations (just before the next dose) are readily measured, but not the average concentration during any given dosage interval, since the latter require several blood samples, but the former require only one sample per dosage interval. One question to be answered by the study performed was whether equation 3 applies if $\bar{C}_{\mathrm{ss}}$ is replaced by $C_{\mathrm{ss}}^{\mathrm{min}}$, where $C_{\mathrm{ss}}^{\mathrm{min}}$ is the minimum concentration at steady state.

\section{EXPERIMENTAL}

Two sets of simulations were performed. In both cases the differential equations were numerically integrated using the Runge-Kutta method and an electronic calculator. Numerical values of the constants used were similar to some of those reported by Richens (5) for phenytoin.

\section{Simulated Intravenous Data}

Equation 5 was numerically integrated for each dosage interval:

$$
-d C / d t=V_{m} C /\left(K_{m}+C\right)
$$

In equation $5, C$ is the simulated plasma concentration at time $t$ after the $n$th dose of size $D$ and the other symbols are as defined in the Theoretical section. Constants used were $V_{m}=15 \mathrm{mg} /$ (liters $\times$ day), $K_{m}=12 \mathrm{mg} /$ liter, $D=200,250,300,400$, and $500 \mathrm{mg}$, corresponding to $C_{0}=5,6.25,7.5$, 10 , and $12.5 \mathrm{mg} /$ liter, respectively, since the assumed volume of distribution, $V_{d}$, was 40 liters. The "dose" was given once a day, hence the dosage interval, $\tau=1$ day, and the dose rates, $D / \tau$, were the same as the doses. The step height employed was 0.01 day. When $D=200, C_{0}=5$ for the first day; for subsequent days, $C_{0}$ was equal to 5 plus the value of $C$ at 
$24 \mathrm{hr}$ after the previous dose. During these simulations, only the maximum, $C_{n}^{\max }$, and minimum, $C_{n}^{\min }$, concentrations for each dose were recorded, where $n$ is the dose number.

\section{Simulated Oral Data}

Equation 6 was numerically integrated for each dosage interval:

$$
d C / d t=k_{a} C_{0} e^{-k_{a} t}-V_{m} C /\left(K_{m}+C\right)
$$

where $k_{a}$ is the first-order rate constant for absorption and the other symbols are as defined above. Constants used were $k_{a}=0.25 \mathrm{hr}^{-1}, V_{m}=12$ $\mathrm{mg} /\left(\right.$ liters $\times$ day), $K_{m}=12 \mathrm{mg} /$ liter, $D=100,150,300,400$, and 600 , corresponding to $C_{0}=1.67,2.5,5,6.67$, and $10 \mathrm{mg} /$ liter, respectively, since the assumed $V_{d}$ was 60 liters. Again $\tau=1$ day, hence the dose rates were the same as the doses. During these simulations, the concentrations at $0,0.5,1,2,4,6,8,12$, and $24 \mathrm{hr}$, as well as the maximum concentration, $C_{n}^{\max }$, and the time of the maximum cocncentration, $t_{n}^{\max }$, were recorded for each dose. The average concentration during each dosage interval, $\bar{C}_{n}$, was estimated by estimating the area under the $C, t$ curve $[\mathrm{mg} /($ liters $\times \mathrm{hr})]$ by trapezoidal rule, then dividing this area by $\tau$ (in this case $24 \mathrm{hr}$ ).

\section{Treatment of Data}

Initial estimates of the asymptotic steady-state concentrations, $C_{\mathrm{ss}}^{\mathrm{min}}$ and $\bar{C}_{\mathrm{ss}}$, were obtained by extrapolating linear plots of $C_{n}^{\min }$ vs. $C_{n+1}^{\min }-$ $C_{n}^{\min }$ or $\bar{C}_{n}$ vs. $\bar{C}_{n+1}-\bar{C}_{n}$ (see later Fig. 2 ), since the concentrations were obtained at equal time intervals $(11,12)$. Initial estimates of the rate parameters, $\lambda_{1}$ and $\lambda_{2}$, were obtained by application of the back-projection technique to the differences, $C_{n+1}^{\min }-C_{n}^{\min }$ or $\bar{C}_{n+1}-\bar{C}_{n}$.

Final estimates of the steady-state concentrations and the $\lambda_{i}$ 's were obtained by nonlinear least-squares fitting of $\bar{C}_{n}, n$ or $C_{n}^{\mathrm{min}}, n$ data to one of equations $7-10$, using the program NONLIN (13) and a high-speed digital computer.

$$
\begin{gathered}
\bar{C}_{n}=\bar{C}_{\mathrm{ss}}\left(1-e^{-\lambda_{1} n}\right) \\
C_{n}^{\min }=C_{\mathrm{ss}}^{\min }\left(1-e^{-\lambda_{1} n}\right) \\
\bar{C}_{n}=C_{1}\left(1-e^{-\lambda_{1} n}\right)+C_{2}\left(1-e^{-\lambda_{2} n}\right) \\
C_{n}^{\min }=C_{1}\left(1-e^{-\lambda_{1} n}\right)+C_{2}\left(1-e^{-\lambda_{2} n}\right)
\end{gathered}
$$

From equation 9 one obtains $\bar{C}_{\mathrm{ss}}=C_{1}+C_{2}$ for $n \rightarrow \infty$ and from equation 10 one obtains $C_{\mathrm{ss}}^{\min }=C_{1}+C_{2}$ for $n \rightarrow \infty$. It should be noted, since $n=1,2$, 
$3, \ldots$, etc., days, that the $\lambda_{i}$ 's have dimension day $^{-1}$. In the fittings the concentrations were weighted $1 / C_{i}$ and $\lambda_{1}<\lambda_{2}$.

The half-life, $\left(t_{1 / 2}\right)_{\lambda_{1}}$, corresponding to each estimated $\lambda_{1}$ value, was obtained by dividing the $\lambda_{1}$ value into the natural logarithm of 2 . For each data set these half-life values were plotted against the corresponding steady-state concentrations.

The steady-state concentrations were also fitted, via NONLIN, to either equation 11 or 12 , also with reciprocal weighting.

$$
\begin{gathered}
C_{\mathrm{ss}}^{\mathrm{min}}=K_{m}^{\mathrm{app}}(D / \tau) /\left\{V_{d} V_{m}^{\mathrm{app}}-(D / \tau)\right\} \\
\bar{C}_{\mathrm{ss}}=K_{m}(D / \tau) /\left\{V_{d} V_{m}-(D / \tau)\right\}
\end{gathered}
$$

Equation 12 is just a rearranged form of equation 3 . In equation $11, K_{m}^{\text {app }}$ and $V_{m}^{\text {app }}$ are operationally useful parameters, but are not the same as the $K_{m}$ and $V_{m}$ used to generate the data.

The parameters of equations 11 and 12 were also estimated by use of various linear transformations of the equations (14-18).

\section{RESULTS}

Figure 1 is a plot of the minimum concentration after the $n$th dose, $C_{n}^{\text {min }}$, vs. the dose number, $n$, for the intravenous simulation. Similar plots (not shown) were obtained when $C_{n}^{\max }$ from the intravenous simulations or $C_{n}^{\max }, \bar{C}_{n}$, and $C_{n}^{\min }$ from the oral simulations were plotted vs. $n$. One can immediately perceive that the higher the dose, the higher the steady-state concentration and the longer the time required to reach that concentration.

If concentrations are measured at equal time intervals, as in the simulations, the difference method, as introduced into pharmacokinetics by Amidon et al. (11), and modified by Wagner and Ayres (12), could be applied to estimate the asymptotic steady-state concentrations from data obtained before steady state was attained. Examples are shown in Fig. 2. During the monitoring of minimum phenytoin concentrations, similar plots to those illustrated in Fig. 2 could be constructed. In Fig. 2 the plots are linear since data of each set were chosen in the dose number range where the approach to steady state is described by single exponential function (equation 8). If all the data of a given set are described by a biexponential equation (equation 9 or 10 ) as $n$ increases, $e^{-\lambda_{2} n} \rightarrow 0$, hence the second term on the right-hand sides of equations 9 and 10 approaches $C_{2}$ and the final approach is monoexponential in all cases. If all or essentially all data of a set where the entire approach is described by a biexponential equation are included in the difference plot, then the difference data may be fitted with the equation of a parabola, as illustrated in Fig. 3. Data shown at the 


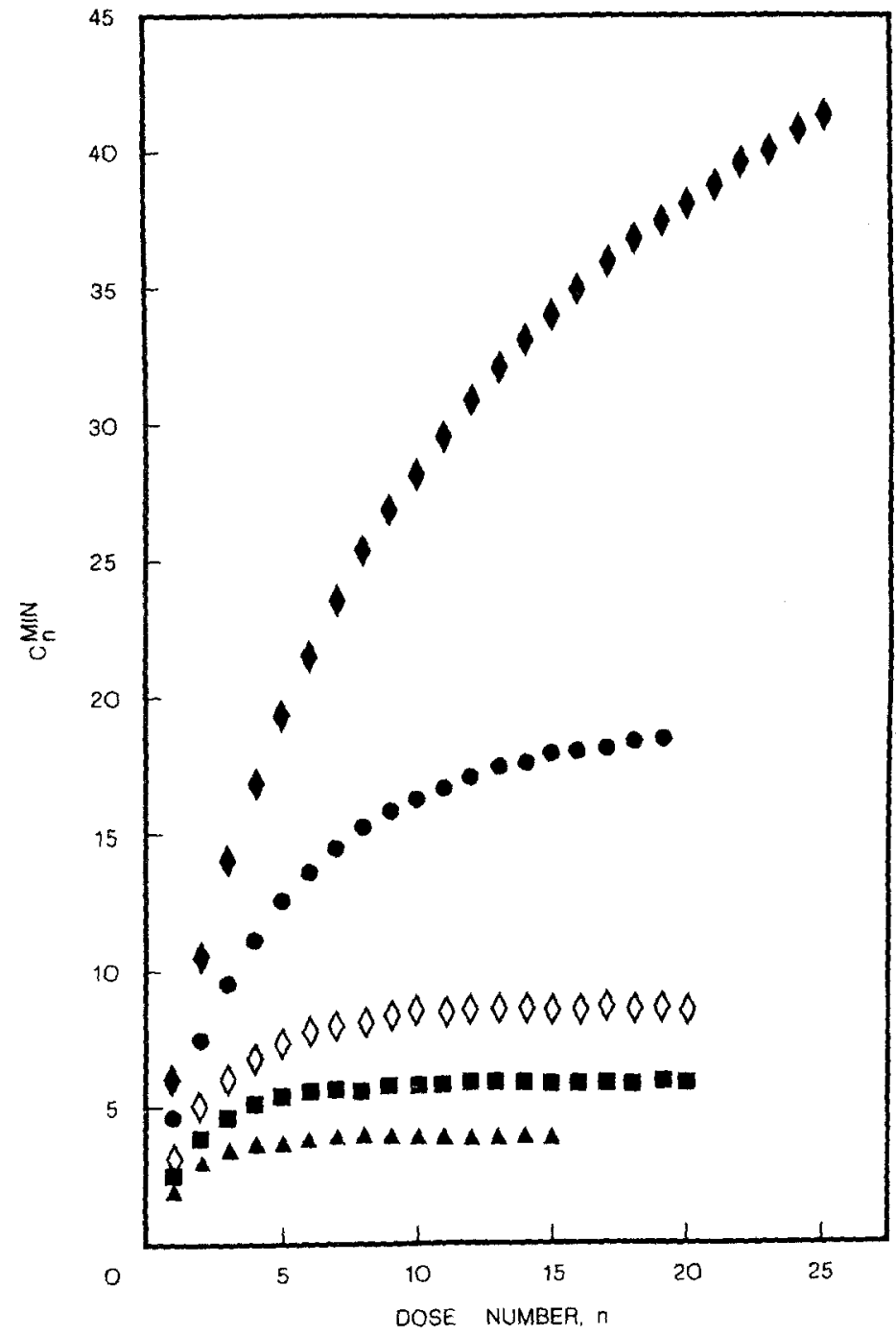

Fig. 1. Plot of minimum concentration after the $n$th dose, $C_{n}^{\min }$, vs, the dose number, $n$, for the intravenous simulation. Symbols and dose rates $(D / \tau, \mathrm{g} /$ day $)$ are $\bullet 0.50 ; 0,0.40 ; \diamond, 0.30 ; 0.25 ; \Delta, 0.20$.

top of Fig. 2 (solid circles) are part of the data shown at the bottom of Fig. 3 (solid squares); in this case, using only the linear data of Fig. 2, the estimated $C_{\mathrm{ss}}^{\mathrm{min}}$ is 19.29 , and, using all the data, fitted by the parabola in Fig. 3, the estimated $C_{s s}^{\min }$ is 19.28 . 


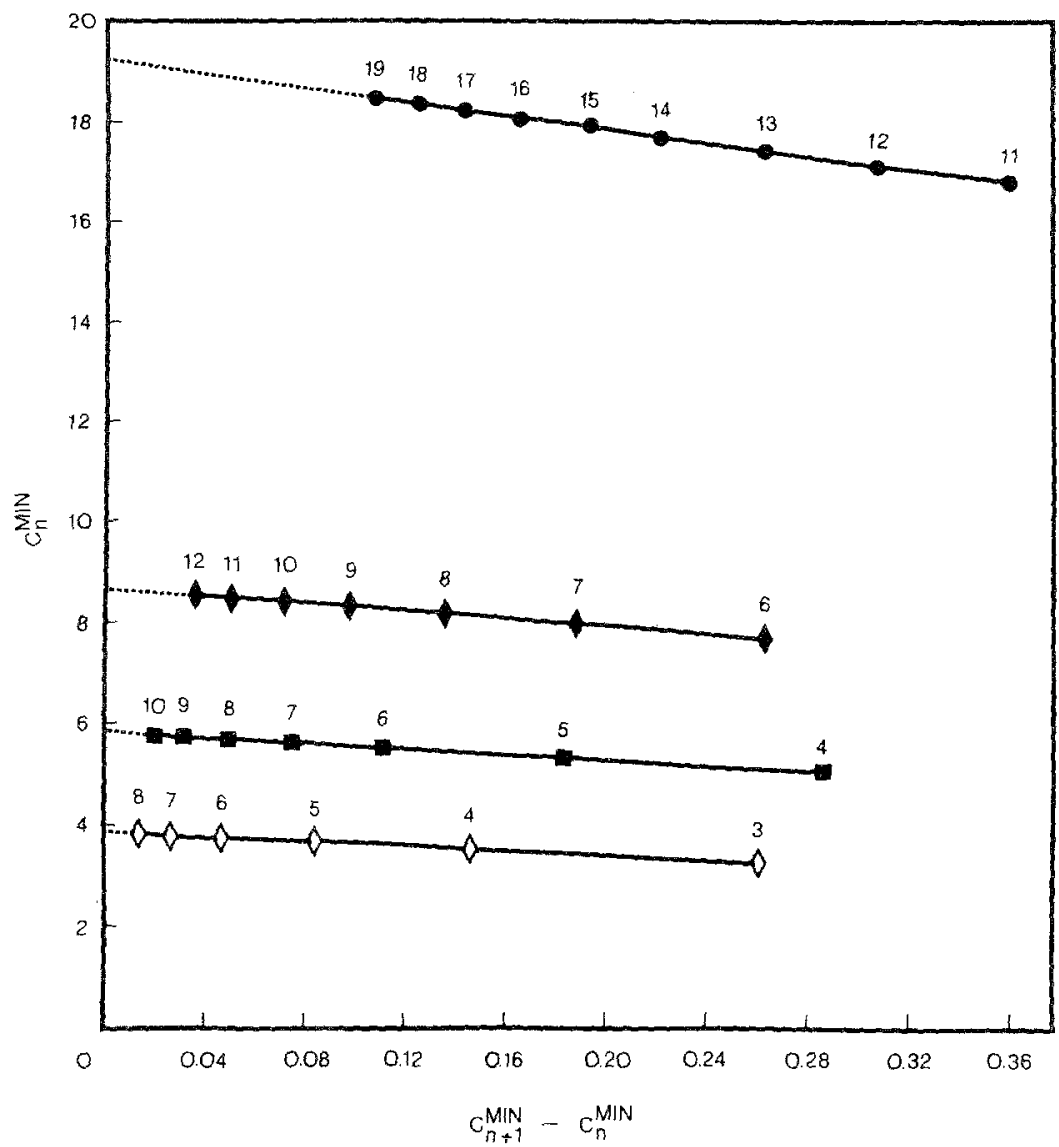

Fig. 2. Application of the "difference method" to estimate asymptotic steady-state concentrations. Examples are from simulated intravenous data. Symbols and dose rates $(D / \tau, \mathrm{g} /$ day $)$ are $0,0.40 ; 0.30 ; \mathbf{D}, 0.25 ; \diamond, 0.20$. Numbers above the points are the dose numbers. Intercepts on the ordinate scale are the estimated $C_{\mathrm{ss}}^{\text {main }}$ values. For example, the equation of the line for the upper (O) set is $C_{n}^{\min }=19.29-7.057$ $\left(C_{n+1}^{\min }-C_{n}^{\min }\right)$, hence $C_{\mathrm{ss}}^{\text {anin }}=19.29$.

Once estimates of the asymptotic $\bar{C}_{\mathrm{ss}}$ and $C_{\mathrm{ss}}^{\mathrm{min}}$ were obtained by the difference method, then the $\ln \left(\bar{C}_{\mathrm{ss}}-\bar{C}_{n}\right), t$ and $\ln \left(C_{\mathrm{ss}}^{\mathrm{min}}-C_{n}^{\mathrm{min}}\right), t$ data were analyzed. It was found that the simulated data resulting from the two lowest doses were described by monoexponential equations (equation 7 or 8), while data for the other doses were described by a biexponential equation (equation 9 or 10). Hence the low-dose data were fitted to equations 7 and 8 , and the higher-dose data were fitted to equations 9 and 10 by nonlinear least-squares regression. Results of the computer fittings 


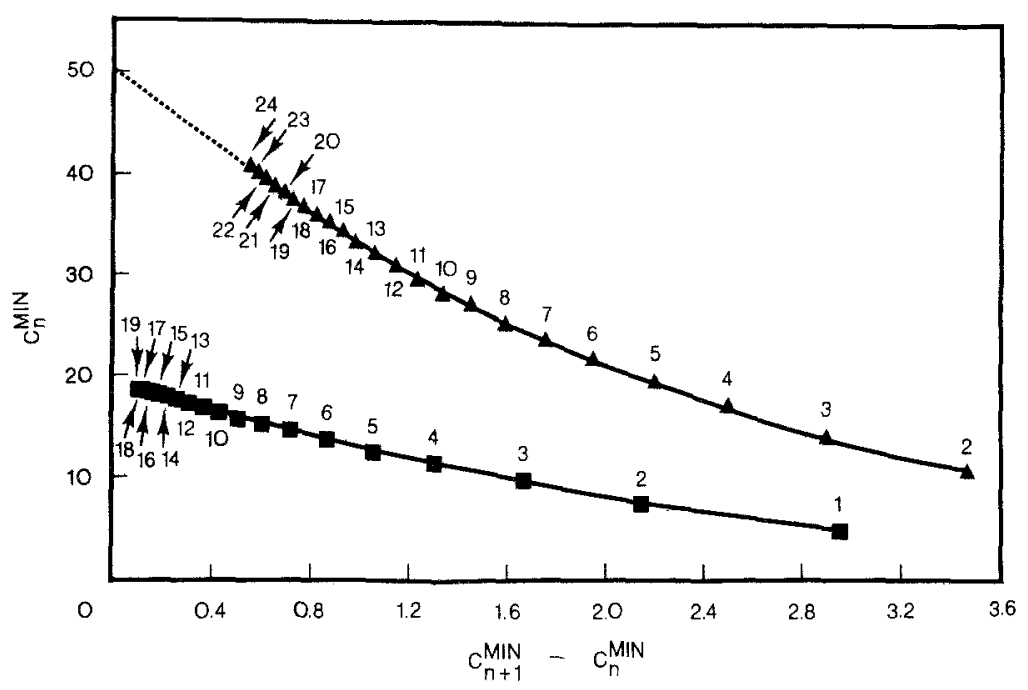

Fig. 3. Fitting of two sets of "difference data" to the equation of a parabola. Examples are from simulated intravenous data. Symbols and dose rates $(D / \tau$, $\mathrm{g} /$ day) are $\boldsymbol{\Lambda}, 0.5 ; \boldsymbol{\square}, 0.4$. For the upper curve the equation is $C_{n}^{\min }=50.04-19.18$ $\left(C_{n+1}^{\min }-C_{n}^{\min }\right)+2.288\left(C_{n+1}^{\min }-C_{n}^{\min }\right)^{2}$, hence the estimated $C_{\mathrm{ss}}^{\min }=50.04$. For the lower curve the equation is $C_{n}^{\min }=19.28-7.233\left(C_{n+1}^{\min }-C_{n}^{\min }\right)+0.8218\left(C_{n+1}^{\min }-\right.$ $\left.C_{n}^{\min }\right)^{2}$, hence the estimated $C_{\mathrm{ss}}^{\min }=19.28$.

are shown in Table I. The monoexponential fittings were excellent, with almost all of the percent deviations being less than $1 \%$ and $r^{2}(1-$ $\Sigma \operatorname{dev}^{2} / \Sigma \mathrm{obs}^{2}$ ) and Corr (correlation coefficient for the linear regression of $\hat{Y}$ on $Y$ ) being equal to 1.000 . Similarly, the biexponential fittings were excellent, with all percent deviations being less than $1 \%$ except those at very low dose numbers, and $r^{2}$ and Corr being equal to 1.000 .

Table II compares the asymptotic steady-state concentrations estimated by the computer-fitting method with those obtained by the difference method. Agreement is excellent in all 15 comparisons.

The half-life obtained from the smaller rate parameter, $\lambda_{1}$, namely $\left(t_{1 / 2}\right)_{\lambda_{1}}$, is approximately linearly related to the steady-state concentration. This is illustrated in Fig. 4 with the $\bar{C}_{\mathrm{ss}}$ data from the oral simulations. The author believes that the deviations from linearity are real and that the straight line is only an approximation to the trends in the data. Similar plots (not shown) for the $C_{\mathrm{ss}}^{\min }$ data from both the intravenous and oral simulations also had similar deviations. The equations of the lines and correlation coefficients $(r)$ are shown as equations 13 and 14. 
Table I. Results of Nonlinear Least-Squares Fitting of $\bar{C}_{n}, n$ and $C_{n}^{\min }, n$ Data

\begin{tabular}{|c|c|c|c|c|c|c|c|}
\hline Data & $\begin{array}{l}\text { Equation } \\
\text { used }\end{array}$ & $\begin{array}{c}D / \tau \\
\text { (g/day) }\end{array}$ & $\begin{array}{l}\text { Steady-state } \\
\text { concentration } \\
\text { (mg/liter) }\end{array}$ & $\begin{array}{c}C_{1} \\
\text { (mg/liter) }\end{array}$ & $\begin{array}{c}C_{2} \\
\text { (mg/liter) }\end{array}$ & $\begin{array}{c}\lambda_{1} \\
\text { (days }^{-1} \text { ) }\end{array}$ & $\begin{array}{c}\lambda_{2} \\
\text { (days }^{-1} \text { ) }\end{array}$ \\
\hline \multirow[t]{5}{*}{ Oral, $\vec{C}_{n}$} & 3 & 0.10 & $\begin{array}{c}1.943^{a} \\
(0.00728)^{b}\end{array}$ & - & - & $\begin{array}{c}0.7003 \\
(0.0108)\end{array}$ & - \\
\hline & 3 & 0.15 & $\begin{array}{c}3.157^{a} \\
(0.00551)\end{array}$ & - & 一 & $\begin{array}{c}0.6333 \\
(0.00531)\end{array}$ & 一 \\
\hline & 5 & 0.30 & $8.481^{a, c}$ & $\begin{array}{c}6.063 \\
(2.227)\end{array}$ & $\begin{array}{c}2.418 \\
(2.271)\end{array}$ & $\begin{array}{c}0.3451 \\
(0.0674)\end{array}$ & $\begin{array}{c}0.8713 \\
(0.405)\end{array}$ \\
\hline & 5 & 0.40 & $14.842^{a, c}$ & $\begin{array}{c}9.604 \\
(1.159)\end{array}$ & $\begin{array}{c}5.238 \\
(1.220)\end{array}$ & $\begin{array}{c}0.2053 \\
(0.0182)\end{array}$ & $\begin{array}{r}0.6116 \\
(0.0787)\end{array}$ \\
\hline & 5 & 0.60 & $56.190^{a, c}$ & $\begin{array}{l}39.728 \\
(0.949)\end{array}$ & $\begin{array}{l}16.462 \\
(2.368)\end{array}$ & $\begin{array}{c}0.04509 \\
(0.00821)\end{array}$ & $\begin{array}{r}0.2907 \\
(0.0300)\end{array}$ \\
\hline \multirow[t]{5}{*}{ Oral, $C_{n}^{\min }$} & 4 & 0.10 & $\begin{array}{c}1.411^{d} \\
(0.00161)\end{array}$ & - & - & $\begin{array}{c}0.7939 \\
(0.00395)\end{array}$ & - \\
\hline & 4 & 0.15 & $\begin{array}{c}2.364 \\
(0.00304)\end{array}$ & - & - & $\begin{array}{c}0.6950 \\
(0.00459)\end{array}$ & - \\
\hline & 6 & 0.30 & $6.910^{d, c}$ & $\begin{array}{c}5.458 \\
(0.0321)\end{array}$ & $\begin{array}{c}1.452 \\
(0.0329)\end{array}$ & $\begin{array}{c}0.3569 \\
(0.00131)\end{array}$ & $\begin{array}{c}1.072 \\
(0.0157)\end{array}$ \\
\hline & 6 & 0.40 & $12.730^{d, c}$ & $\begin{array}{c}5.985 \\
(2.923)\end{array}$ & $\begin{array}{c}6.745 \\
(3.033)\end{array}$ & $\begin{array}{c}0.1799 \\
(0.0514)\end{array}$ & $\begin{array}{c}0.4445 \\
(0.0907)\end{array}$ \\
\hline & 6 & 0.60 & $52.056^{d, c}$ & $\begin{array}{l}39.431 \\
(0.567)\end{array}$ & $\begin{array}{l}12.625 \\
(1.114)\end{array}$ & $\begin{array}{c}0.04816 \\
(0.00438)\end{array}$ & $\begin{array}{c}0.3511 \\
(0.0254)\end{array}$ \\
\hline \multirow[t]{5}{*}{ i.v., $C_{n}^{\text {mins }}$} & 4 & 0.20 & $\begin{array}{c}3.829^{d} \\
(0.00750)\end{array}$ & - & - & $\begin{array}{c}0.6457 \\
(0.00626)\end{array}$ & - \\
\hline & 4 & 0.25 & $\begin{array}{c}5.792 \\
(0.0128)\end{array}$ & - & - & $\begin{array}{c}0.5298 \\
(0.00606)\end{array}$ & - \\
\hline & 6 & 0.30 & $8.724^{d, c}$ & $\begin{array}{l}10.952 \\
(6.655)\end{array}$ & $\begin{array}{c}-2.227 \\
(6.726)\end{array}$ & $\begin{array}{c}0.3623 \\
(0.2053)\end{array}$ & $\begin{array}{r}0.3390 \\
(0.8972)\end{array}$ \\
\hline & 6 & 0.40 & $19.161^{d, c}$ & $\begin{array}{l}14.797 \\
(0.121)\end{array}$ & $\begin{array}{c}4.364 \\
(0.141)\end{array}$ & $\begin{array}{c}0.1653 \\
(0.00174)\end{array}$ & $\begin{array}{r}0.7245 \\
(0.0182)\end{array}$ \\
\hline & 6 & 0.50 & $48.113^{d, c}$ & $\begin{array}{l}39.793 \\
(0.131)\end{array}$ & $\begin{array}{c}8.319 \\
(0.299)\end{array}$ & $\begin{array}{c}0.06967 \\
(0.00144)\end{array}$ & $\begin{array}{r}0.5146 \\
(0.0168)\end{array}$ \\
\hline
\end{tabular}

${ }^{a}$ Values of $\bar{C}_{\mathrm{ss}}$.

${ }^{b}$ Numbers in parentheses are standard deviations of the estimated parameters.

${ }^{c} C_{1}+C_{2}$.

${ }^{d}$ Values of $C_{\mathrm{ss}}^{\mathrm{min}}$.

Oral simulation:

$$
\left(t_{1 / 2}\right)_{\lambda_{1}}=0.340+0.270 C_{\mathrm{ss}}^{\min } \quad r=0.9996
$$

Intravenous simulation:

$$
\left(t_{1 / 2}\right)_{\lambda_{1}}=0.216+0.203 C_{\mathrm{ss}}^{\min } \quad r=0.9998
$$

In therapeutic drug monitoring it may be more realistic to consider, say, $95 \%$ of the steady-state concentration. Figure 5 is a plot of the number of doses required to reach $95 \%$ of the minimum steady-state concentration 
Table II. Comparison of Steady-State Concentrations Estimated by Computer Fitting of All of the Data of Each Set and Those Estimated by the Difference Method

\begin{tabular}{|c|c|c|c|c|c|}
\hline \multirow[b]{2}{*}{ Data } & \multirow[b]{2}{*}{$\begin{array}{c}D / \tau \\
(\mathrm{g} / \text { day })\end{array}$} & \multicolumn{2}{|c|}{ Steady-state concentration } & \multicolumn{2}{|c|}{ Data points used $(n)$} \\
\hline & & Computer & $\begin{array}{l}\text { Difference } \\
\text { method }\end{array}$ & Computer & $\begin{array}{c}\text { Difference } \\
\text { method }\end{array}$ \\
\hline \multirow[t]{5}{*}{ Oral, $\bar{C}_{n}$} & 0.10 & 1.943 & $1.934^{a}$ & $0-10$ & $4-8$ \\
\hline & 0.15 & 3.157 & $3.153^{a}$ & $0-15$ & $4-11$ \\
\hline & 0.30 & 8.481 & $8.516^{a}$ & $0-16$ & $8-16$ \\
\hline & 0.40 & 14.842 & $14.867^{a}$ & $0-21$ & $13-21$ \\
\hline & 0.60 & 56.190 & $56.26^{a}$ & $0-30$ & $27-30$ \\
\hline \multirow[t]{5}{*}{ Oral, $C_{n}^{\min }$} & 0.10 & 1.411 & $1.413^{a}$ & $0-10$ & $1-10$ \\
\hline & 0.15 & 2.364 & $2.367^{a}$ & $0-15$ & $1-12$ \\
\hline & 0.30 & 6.910 & $6.914^{a}$ & $0-16$ & $9-16$ \\
\hline & 0.40 & 12.730 & $12.762^{a}$ & $0-21$ & $14-21$ \\
\hline & 0.60 & 52.056 & $51.868^{a}$ & $0-30$ & $17-30$ \\
\hline \multirow[t]{5}{*}{ i.v., $C_{n}^{\min }$} & 0.20 & 3.829 & $\begin{array}{c}3.843^{a} \\
(3.842)^{a, b}\end{array}$ & $0-15$ & $\begin{array}{c}3-15 \\
(3-9)^{b}\end{array}$ \\
\hline & 0.25 & 5.792 & $\begin{array}{r}5.822^{a} \\
(5.820)^{a}\end{array}$ & $0-20$ & $\begin{array}{c}4-20 \\
(4-11)^{b}\end{array}$ \\
\hline & 0.30 & 8.724 & $\begin{array}{r}8.636^{a} \\
(8.631)^{a}\end{array}$ & $0-20$ & $\begin{array}{c}6-20 \\
(6-13)^{b}\end{array}$ \\
\hline & 0.40 & 19.161 & $\begin{array}{c}19.288^{a} \\
(19.278)^{c}\end{array}$ & $0-20$ & $\begin{array}{c}11-20 \\
(1-20)^{c}\end{array}$ \\
\hline & 0.50 & 48.113 & $50.040^{c}$ & $0-25$ & $2-25$ \\
\hline
\end{tabular}

${ }^{a}$ Linear plots (see examples in Fig. 2).

${ }^{b}$ Numbers in parentheses in the fourth column are estimates made with the smaller number of data points in parentheses in last column.

${ }^{c}$ Estimates made by fitting of a parabola to the difference data.

vs. $0.95 C_{\mathrm{ss}}^{\min }$ for the intravenous simulation. The variables are linearly related:

$$
n_{0.95}=2.15+0.827\left(0.95 C_{\mathrm{ss}}^{\min }\right) \quad r=1.00
$$

Similar plots using data from the oral simulations did not exhibit as good linearity, but the trends were the same.

Figure 6 shows results of fitting the computer-derived values of $C_{\mathrm{ss}}^{\min }$ and $\bar{C}_{\text {ss }}$ from the oral simulated data to equations 11 and 12 , respectively. The estimated parameters are shown in Table III, where they are compared with estimates made using various linear transformations of equations 11 and 12 . Computer fitting of the $\bar{C}_{\mathrm{ss}}, D / \tau$ data gave an estimated value of $V_{d} V_{m}$ of $0.731 \mathrm{~g} /$ day, which corresponds to a $V_{m}$ value of 12.18 , which is $1.5 \%$ higher than the known value used in the simulation. The estimated value of $K_{m}$ was 12.23 , which is $1.9 \%$ higher than the known value of 12 . These small errors could readily be accounted for as a result of using the trapezoidal rule to estimate the areas from just a few 


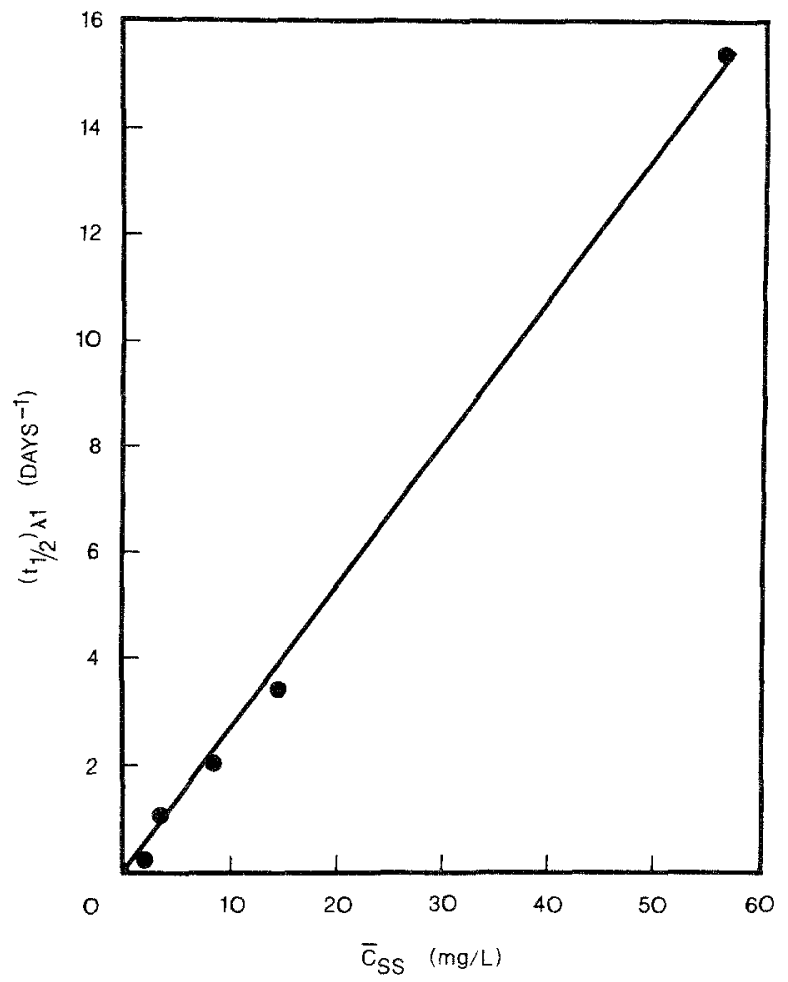

Fig. 4. Plot of the half-life, $\left(t_{1 / 2}\right)_{\lambda_{1}}$, from the smallest rate parameter, $\lambda_{1}$, vs. the average steady-state concentration, $\vec{C}_{\mathrm{ss}}$, for the oral simulations. The equation of the line is $\left(t_{1 / 2}\right)_{\lambda_{1}}=$ $0.270 \overline{\mathcal{C}}_{\mathrm{ss}}$.

points and the errors involved in the fitting. Thus equation 12 does apply to oral data, and the true kinetic constants, $V_{m}$ and $K_{m}$, are estimated. But in the computer fitting of $C_{\mathrm{ss}}^{\min }, D / \tau$ data, shown in Fig. 6, the estimated value of $V_{d} V_{m}^{\text {app }}$ was 0.709 , corresponding to a $V_{m}^{\text {app }}$ value of 11.82 , which is $1.5 \%$ lower than the known value of $V_{m}$, and the estimated value of $K_{m}^{\text {app }}$ was 9.45 , which is $27 \%$ lower than the known value of $K_{m}$ of 12 . Figure 7 shows the results of fitting $C_{\mathrm{ss}}^{\min }, D / \tau$ data from the intravenous simulation to equation 11. The estimated parameters are shown in Table III. The estimated value of $V_{d} V_{m}^{\text {app }}$ was 0.585 , corresponding to an estimated value of $V_{m}^{\text {app }}$ of 14.625 , which is $2.5 \%$ lower than the known value of $V_{m}$ of 15 ; the estimated value of $K_{m}^{\text {app }}$ was 8.25 , which is $31 \%$ lower than the $K_{m}$ value of 12 . This explains why the "true" kinetic constants, $V_{m}$ and $K_{m}$, appear in equation 12 , but only apparent constants, $V_{m}^{\text {app }}$ and $K_{m}^{\text {app }}$, appear in equation 11. Thus $V_{m}^{\text {app }}$ and $K_{m}^{\text {app }}$ are operationally useful parameters 


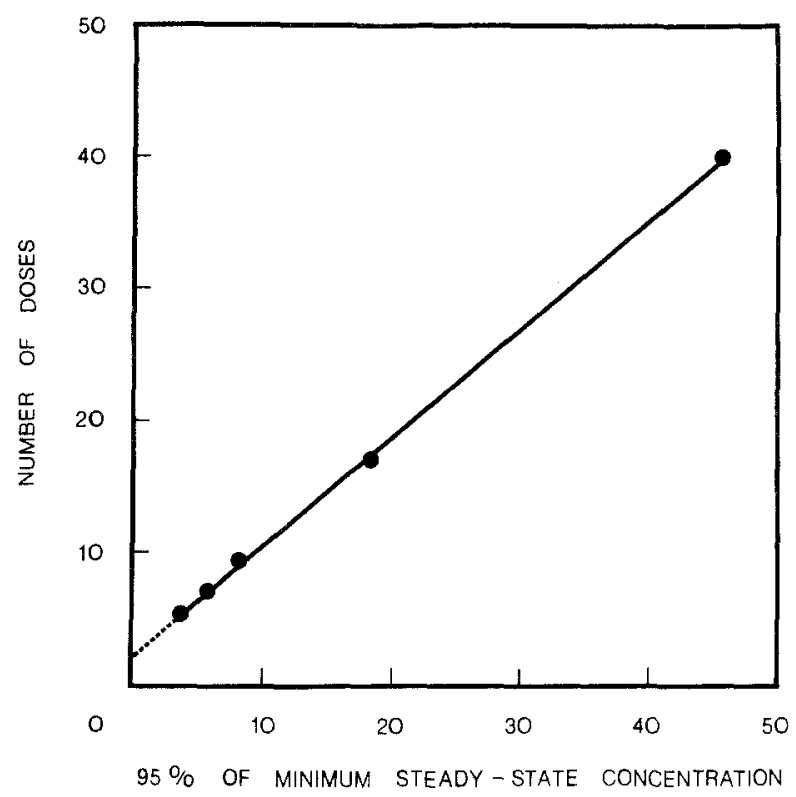

Fig. 5. Plot of the number of doses $\left(n_{0.95}\right)$ required to reach $95 \%$ of the minimum steady-state concentration vs. $95 \%$ of the minimum steady-state concentration using data from the intravenous simulation. Equation of the line is in the text (equation 11).

derived from minimum steady-state concentrations, but are not the actual enzyme constants. This, therefore, applies to the same type of constants reported by Richens (5), Ludden et al. (6), and Mullen (7). It is also of interest to see, in some cases, how much the constants estimated by other methods differ from those estimated by nonlinear least-squares fitting (Table III).

\section{DISCUSSION}

The simulations have shown that when elimination kinetics is that of Michaelis and Menten the rate of accumulation is either mono- or biexponential, with the half-life corresponding to the smaller rate parameter being approximately linearly related to the final steady-state concentration. Thus, as the dose rate is increased, it requires proportionately more time to reach a given proportion of the final steady-state concentration. Since parallel Michaelis-Menten metabolite formation paths (19) and parallel Michaelis-Menten and first-order elimination pathways (20) 


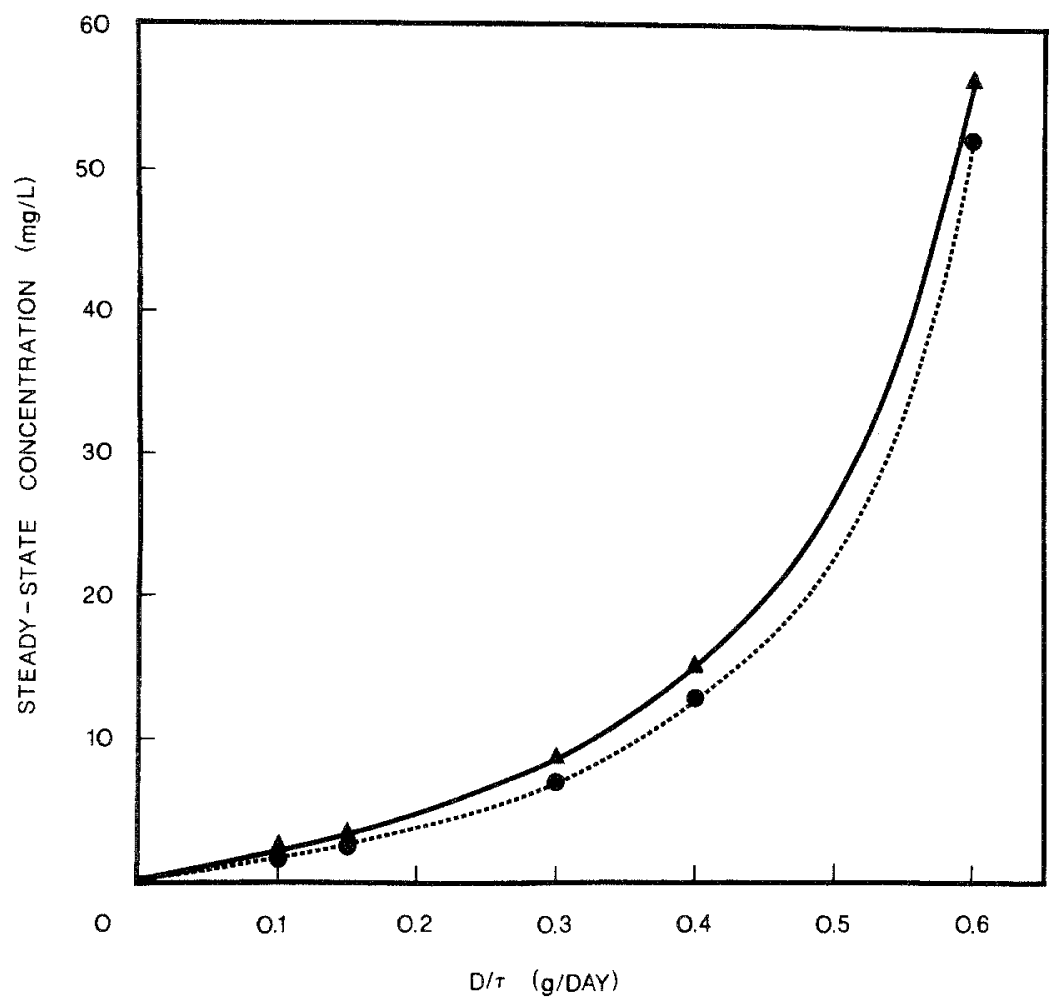

Fig. 6. Results of nonlinear least-squares fitting of simulated oral data to equations 7 and $8 . \Delta-\mathbf{\Lambda}, \bar{C}_{\mathrm{ss}}$ data (equation 8); $--0, C_{\mathrm{ss}}^{\mathrm{min}}$ data (equation 7). See Table III for estimated parameters.

frequently act like "pooled" Michaelis-Menten paths, the results of these simulations have even broader applicability than just to simple MichaelisMenten elimination. It was also found that the difference method (see Figs. 2 and 3) could be applied to the $C_{n}^{\max }, n$ data generated in both the oral and intravenous simulations to estimate $C_{\mathrm{ss}}^{\max }$ values. The latter values were also well fitted to an equation analogous to equation 11 except that $C_{\mathrm{ss}}^{\text {max }}$ replaced $C_{\mathrm{ss}}^{\mathrm{min}}$; in these cases, the $V_{m}^{\text {app }}$ and $K_{m}^{\text {app }}$ values which were estimated were different from those estimated from the corresponding $C_{\mathrm{ss}}^{\min }$ data.

The results of this study indicate that the statement of Eadie (10) with respect to the rate of accumulation of phenytoin is incorrect. In the monitoring of phenytoin serum concentrations, different investigators appear to have been allowing different times before measuring what they call "steady-state concentrations." Richens (5) stated: "The minimum 
Table III. Parameters Estimated by Computer Fitting of Data to Equation 11 and 12 or by Use of Various Linear Transformations of Those Equations

\begin{tabular}{|c|c|c|c|c|c|}
\hline \multirow[b]{2}{*}{ Data } & \multirow[b]{2}{*}{ Method } & \multicolumn{2}{|c|}{ Variables for plot } & \multirow{2}{*}{$\begin{array}{l}V_{d} V_{m}{ }^{a} \\
\text { (g/day) }\end{array}$} & \multirow{2}{*}{$\begin{array}{c}K_{m}^{b} \\
\text { (mg/liter) }\end{array}$} \\
\hline & & Abscissa & Ordinate & & \\
\hline \multirow[t]{7}{*}{ Oral, $\bar{C}_{\mathrm{ss}}$} & $\begin{array}{l}\text { Computer fitting with } \\
\text { equation } 12\end{array}$ & $D / \tau$ & $\bar{C}_{\mathrm{ss}}$ & $\begin{array}{l}0.731 \\
(0.00047)\end{array}$ & $\begin{array}{l}12.23 \\
(0.0367)\end{array}$ \\
\hline & $\begin{array}{l}\text { Cornish-Bowden and } \\
\text { Eisenthal (14) }\end{array}$ & $\bar{C}_{\mathrm{ss}}$ & $D / \tau$ & 0.731 & 12.25 \\
\hline & Lineweaver-Burk (15) & $1 / \bar{C}_{\mathrm{ss}}$ & $1 /(D / \tau)$ & 0.693 & 11.07 \\
\hline & Woolf $(16)$ & & $\bar{C}_{\mathrm{ss}} /(D / \tau)$ & 0.731 & 12.23 \\
\hline & Eadie (17) & $(D / \tau) / \bar{C}_{\mathrm{ss}}$ & $D / \tau$ & 0.731 & 12.23 \\
\hline & Scatchard (18) & $D / \tau$ & $(D / \tau) / \bar{C}_{\mathrm{ss}}$ & 0.731 & 12.23 \\
\hline & & & & $\begin{array}{l}V_{d} V_{m}^{\text {app }} \\
\text { (g/day) }\end{array}$ & $\begin{array}{c}K_{m}^{\text {app }} \\
(\mathrm{mg} / \text { liter })\end{array}$ \\
\hline \multirow[t]{6}{*}{ Oral, $C_{\mathrm{ss}}^{\mathrm{min}}$} & $\begin{array}{l}\text { Computer fitting with } \\
\text { equation } 11\end{array}$ & $D / \tau$ & $C_{\mathrm{ss}}^{\min }$ & $\begin{array}{c}0.709 \\
(0.0047)\end{array}$ & $\begin{array}{l}9.45 \\
(0.347)\end{array}$ \\
\hline & $\begin{array}{l}\text { Cornish-Bowden and } \\
\text { Eisenthal (14) }\end{array}$ & $C_{\mathrm{ss}}^{\min }$ & $D / \tau$ & 0.654 & 8.08 \\
\hline & Lineweaver-Burk (15) & $1 / C_{\mathrm{ss}}^{\min }$ & $1 /(D / \tau)$ & 0.653 & 7.85 \\
\hline & Woolf $(16)$ & $C_{\mathrm{ss}}^{\min }$ & $C_{\mathrm{ss}}^{\min } /(D / \tau)$ & 0.701 & 8.95 \\
\hline & Eadie (17) & $(D / \tau) / C_{\mathrm{ss}}^{\min }$ & $D / \tau$ & 0.681 & 8.39 \\
\hline & Scatchard (18) & $D / \tau$ & $(D / \tau) / C_{\mathrm{ss}}^{\min }$ & 0.681 & 8.39 \\
\hline \multirow[t]{6}{*}{ i.v., $C_{\mathrm{ss}}^{\min }$} & $\begin{array}{l}\text { Computer fitting with } \\
\text { equation } 11\end{array}$ & & & $\begin{array}{l}0.585^{d} \\
(0.0078)\end{array}$ & $\begin{array}{l}8.25 \\
(0.519)\end{array}$ \\
\hline & $\begin{array}{l}\text { Cornish-Bowden and } \\
\text { Eisenthal (14) }\end{array}$ & \multicolumn{2}{|c|}{$\begin{array}{c}\text { See } \\
\text { directly }\end{array}$} & 0.548 & 6.95 \\
\hline & Lineweaver-Burk (15) & \multirow{4}{*}{\multicolumn{2}{|c|}{ above }} & 0.546 & 6.75 \\
\hline & Woolf $(16)$ & & & 0.578 & 7.80 \\
\hline & Eadie (17) & & & 0.559 & 7.12 \\
\hline & Scatchard (18) & & & 0.562 & 7.21 \\
\hline
\end{tabular}

${ }^{a}$ Actual value used in the simulation was $(60 \times 12) / 1000=0.720 \mathrm{~g} /$ day.

${ }^{b}$ Actual value used in the simulation was $12 \mathrm{mg} / \mathrm{liter}$.

'Their equations 5 and 6 were used with all possible pairs of values; the reported value is the median.

${ }^{d}$ Actual value used in the simulation was $(40 \times 15) / 1000=0.600 \mathrm{~g} / \mathrm{day}$.

information needed is one accurate serum level estimation in steady state, i.e. after at least 2 weeks on a constant intake of the drug. The time of day at which the sample is taken has not been allowed for because phenytoin is absorbed and metabolized relatively slowly. The usual fluctuation in serum levels seen throughout the day seldom exceeds $20 \%$, particularly at therapeutic serum levels." Ludden et al. (6) stated: "Steady state serum phenytoin levels were determined at least 3 but usually 4 wk after a change 


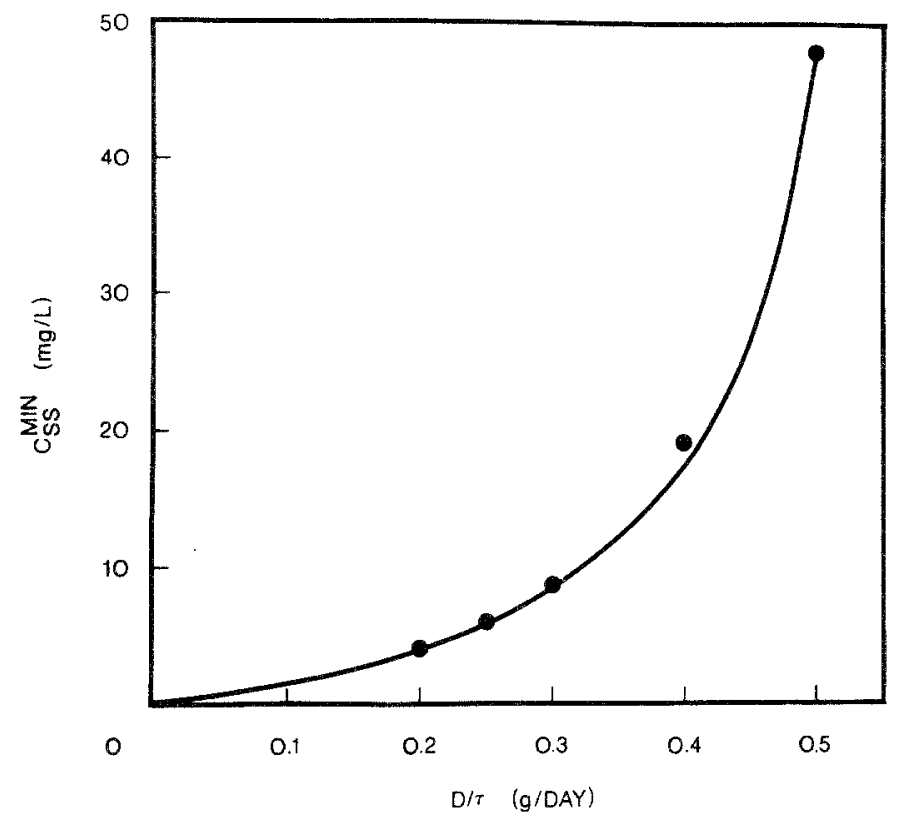

Fig. 7. Results of nonlinear least-squares fitting of simulated intravenous data to equation 7. See Table III for estimated parameters.

in phenytoin dosage." The simulations show that the time that needs to be allowed depends on the dose rate of the drug.

If one wishes to estimate $V_{m}^{\text {app }}$ and $K_{m}^{\text {app }}$ for a given patient, as done by Richens (5), Ludden et al. (6), and Mullen (7), then the simulations suggest a procedure as follows. Minimum steady-state concentrations, $C_{n}^{\text {min }}$, just before the next dose, should be measured on consecutive days, starting about 4-6 days after uniform therapy has been initiated or a change in dosage regimen has taken place. A difference plot should be prepared; if the difference data are linear (like the data in Fig. 2), then an estimate of $C_{\mathrm{ss}}^{\mathrm{min}}$ for a given dose rate is readily made. If the dose rate is high and/or data are collected too early, the difference plot may be curved (like data in Fig. 3), in which case one may either fit a parabola to make an estimate of $C_{\mathrm{ss}}^{\mathrm{min}}$ or keep collecting data until the plot becomes linear, then extrapolate the linear portion. Thus the pharmacokinetic equations (e.g., equation 11) require estimates of $C_{\mathrm{ss}}^{\min }$ for various $D / \tau$ values; use of just some $C_{n}^{\min }$ values, as apparently has been done to date, would lead to biased results.

Assay error involved in measurement of the $C_{n}^{\min }$ values does not necessarily lead to errors in estimated parameters. A set of $C_{n}^{\min }, n$ values 
was generated with equation 8 using $C_{\mathrm{ss}}^{\min }=100$ and $\lambda_{1}=0.1$, then $5 \%$ random error was added so that values were either $95 \%$ (-error) or $105 \%$ (+error) of the actual $C_{n}^{\min }$ values; for $n=1,2,3,4,7,10,15,20,25$, and 30 , the error was,,,,,,,,-++-+--+- , and + , respectively. Computer fitting of the $C_{n}^{\min }$ data with the $5 \%$ random error to equation 11 gave estimates as follows: $C_{\mathrm{ss}}^{\min }=100.00$ and $\lambda_{1}=0.1000$. Thus with inclusion of $5 \%$ random error in the data the theoretical constants were exactly estimated.

It is interesting that the $K_{m}^{\mathrm{app}}$ values, estimated from $C_{\mathrm{ss}}^{\min }$ values, are quite different than the actual $K_{m}$ values, while the $V_{m}^{\text {app }}$ values, estimated from $C_{\mathrm{ss}}^{\min }$ values, are only slightly different than the actual $V_{m}$ values. Also, estimates of $V_{d} V_{m}^{\text {app }}$ and $K_{m}^{\text {app }}$, obtained by the method of CornishBowden and Eisenthal and via various linear transformations of equations 11 from $C_{n}^{\min }$ data, were all lower than estimates of the same parameters obtained by nonlinear least-squares fitting with reciprocal weighting. However, estimates of $V_{d} V_{m}$ and $K_{m}$ obtained by all methods agreed quite well except those obtained via the double reciprocal or Lineweaver-Burk (15) transformation, which gave the lowest estimates in each case.

In the simulations the ratio $C_{n}^{\max } / C_{n}^{\min }$ was always highest for $n=1$; then as $n$ increased the ratio decreased and approached an asymptotic value at higher values of $n$. The asymptotic value of the ratio was lower the higher the dose. For the intravenous data the asymptotic ratios were 2.30 , $1.87,1.53,1.29$, and 1.15 for dose rates of $0.2,0.3,0.4,0.5$, and 0.6 , respectively. For the oral data the asymptotic ratios were $1.58,1.54,1.38$, 1.28 , and 1.12 for dose ratios of $0.1,0.15,0.3,0.4$, and $0.6 \mathrm{~g} /$ day, respectively. Hence in the monitoring of phenytoin serum concentrations one would expect the degree of fluctuation in the concentrations throughout the day to be both dose and concentration dependent. These data support measurement of minimum concentrations just before the next dose.

\section{REFERENCES}

1. L. M. Michaelis and M. L. Menten. Die Kinetik der Invertinwirkung. Biochem. $Z$. 49:333-369 (1913).

2. F. Lundquist and $\mathrm{H}$. Wolthers. The kinetics of alcohol elimination in man. Acta Pharmacol. Toxicol. 14:265-289 (1958).

3. J. G. Wagner. A modern view of pharmacokinetics. J. Pharmacokin. Biopharm. 1:363401 (1973).

4. N. Gerber and J. G. Wagner. Explanation of dose-dependent decline of diphenylhydantoin plasma levels by fitting to the integrated form of the Michaelis-Menten equation. Res. Commun. Chem. Pathol. Pharmacol. 3:455-466 (1972).

5. A Richens. A study of the pharmacokinetics of phenytoin (diphenylhydantoin) in epileptic patients, and the development of a nomogram for making dose increments. Epilepsia 16:627-646 (1975). 
6. T. M. Ludden, J. P. Allen, W. A. Valutsky, A. V. Vicuna, J. M. Nappi, S. F. Hoffman, J. E. Wallace, D. Lalka, and J. L. McNay. Individualization of phenytoin dosage regimens. Clin. Pharmacol. Ther. 21:287-293 (1977).

7. P. W. Mullen. Optimal phenytoin therapy: A novel technique for individualizing dosage. Clin. Pharmacol. Ther. 23:228-232 (1978).

8. J. G. Wagner. Properties of the Michaelis-Menten equation and its integrated form which are useful in pharmacokinetics. J. Pharmacokin. Biopharm. 1:103-121 (1973).

9. T. Tsuchiya and G. Levy. Relationship between dose and plateau levels of drugs eliminated by parallel first order and capacity-limited kinetics. J. Pharm. Sci. 61:541-544 (1972).

10. M. J. Eadie. Plasma level monitoring of anticonvulsants. Clin. Pharmacokin. 1:52-66 (1976).

11. G. L. Amidon, M. J. Paul, and P. G. Welling. Model-independent prediction methods in pharmacokinetics: Theoretical considerations. Math. Biosci. 25:259-272 (1975).

12. J. G. Wagner and J. W. Ayres. Bioavailability assessment: Methods to estimate total area (AUC $0-\infty$ ) and total amount excreted $\left(A_{e}^{\infty}\right)$ and importance of blood sampling scheme with application to digoxin. J. Pharmacokin. Biopharm. 5:533-557 (1977).

13. C. M. Metzler. NONLIN: A Computer Program for Parameter Estimation in Nonlinear Situations, Technical Report No. 7292/69/7292/005, Nov. 25, 1969, Upjohn Co., Kalamazoo. Mich.

14. A Cornish-Bowden and R. Eisenthal. Statistical considerations in the estimation of enzyme kinetic parameters by the direct linear plot and other methods. Biochem. $J$. 139:721-730 (1974).

15. H. Lineweaver and D. Burk. The determination of enzyme dissociation constants. J. Am. Chem. Soc. 56:658-666 (1934).

16. J. B. S. Haldane. Graphical methods in enzyme chemistry. Nature 179:832 (1957).

17. G. S. Eadie. The inhibition of cholinesterase by physostigmine and prostigmine. J. Biol. Chem. 146:85-93 (1942).

18. G. Scatchard. The attractions of proteins for small molecules and ions. Ann. N.Y. Acad. Sci. 51:660-672 (1949). 